\title{
Introduction: The Beginnings of Metallurgy in Global Perspective
}

\author{
Christopher P. Thornton • Benjamin W. Roberts
}

Published online: 15 October 2009

(C) Springer Science+Business Media, LLC 2009

The 'beginnings of metallurgy' has been a topic of considerable interest for over a century. Due to the relatively good preservation of metal artifacts and the modern values attached to metals, metal artifact typologies often served as the very basis for prehistoric sequences during the late nineteenth and early twentieth century. In many ways, it was V. Gordon Childe $(1930,1944)$ who placed metallurgical technology at the forefront, arguing as he did for the roles of 'itinerant metal smiths' and bronze production in the rise of social elites and complex societies (cf. Wailes 1996). Childe (1939) was also one of the first to systematically argue for the diffusion of metallurgy from the Near East to the rest of Eurasia. This diffusionist perspective was adopted by a number of prominent scholars of ancient metallurgy, notably Wertime (1964, 1973a, b), Smith (1977), Muhly (1988), and Chernykh (1992), who all felt that the technological knowledge necessary to transform ores into metal was too complex to have been invented twice.

Criticism of the ex oriente lux paradigm came first from Europe, where Renfrew (1969, 1973, 1986) used radiocarbon dates to demonstrate that early European metallurgical sites were in fact older than similar sites in the Near East. Not surprisingly, other objections to the diffusionist perspective were raised by scholars working in areas far removed from the Middle East, including in China (e.g., Barnard 1961, 1993), in Africa (e.g., Trigger 1969), and most especially in the New World (e.g., Lechtman 1979, 1980). However, even important cross-regional volumes on early metallurgy (e.g., Wertime and Muhly 1980; Maddin 1988; Hauptmann et al. 1999), which have demonstrated most effectively that metallurgy did not follow a single developmental trajectory in every society, have done little to quell the predominance of diffusionist models and other Childean theories of elite dominance, core-periphery dynamics, and specialized craftspeople.

With this in mind, invitations were sent to fifteen scholars of early metallurgy who had previously demonstrated an ability to combine archaeometrical analysis, archaeological

\footnotetext{
C. P. Thornton $(\bowtie)$

Department of Anthropology, University of Pennsylvania, Philadelphia, PA, USA

e-mail: cpt2@sas.upenn.edu
}

B. W. Roberts

Department of Prehistory and Europe, The British Museum, London, UK

e-mail: BRoberts@thebritishmuseum.ac.uk 
fieldwork, and anthropological interpretation to reach a more holistic understanding of the interaction between metals and societies. Critical to the success of this workshop was the inclusion of scholars from both the Old and New Worlds-a combination that occurs too infrequently in archaeology as a whole. The authors were asked to provide a brief synthetic overview of the development of metal use and production in their regions; a review of the dominant models and theories used in their regions to understand how metal was produced and consumed; and a presentation of any new models and theories that address the relationship between ancient technologies and ancient societies.

The submitted papers were discussed at the 73rd meeting of the Society for American Archaeology held in Vancouver, Canada, on 26th-30th March 2008. Vincent Pigott and Dorothy Hosler served as discussants, while those in attendance included Kathy Ehrhardt (Eastern United States), Izumi Shimada (South America), Ben Roberts (Western Europe), Augustin Holl (Western Africa), Chris Thornton (Iran), Brett Hoffman and Heather Miller (Indus Valley), Praveena Gullapalli (Southern India), Bryan Hanks (Eurasian Steppe), Kathy Linduff (Northeast Asia), and Joyce White (Southeast Asia). David Killick (East and South Africa) and Jonathan Golden (Levant) could not attend the session, but submitted papers of significance to the general discussion. In front of a large and varied audience, the panelists answered questions about their regions and their theoretical perspectives, providing an important addendum to these seminal papers that will be summarized here.

One of the key topics of discussion at the SAA meeting was 'origins' and the usefulness of independent invention versus diffusion debates in studies of ancient technology. Whether taking an indigenous or a migrationist viewpoint on the origins of metallurgy in their regions, the authors have eschewed simplistic culture history models in favor of more nuanced discussion on the mechanisms of technological and cultural transfer, the adoption and adaptation of new materials and techniques, and the importance of other existing crafts in the social acceptance of a new technology (see also Roberts et al. 2009). More than anything else during the discussion and in the papers, the way the authors approached the old and somewhat hackneyed topic of origins demonstrates how far studies of ancient metallurgy have come in the past few decades.

Another important area of discussion was the role of elites in the development of metallurgy (or, the role of metals in the development of elites). In contrast with the Childean view, which accords critical importance to metals in the rise of complex societies, none of the authors expressed a belief in metals as necessary to the construction of an elite class, nor did they argue that an elite class is needed for the development of metallurgical production. That is not to say that metals did not play any role in the construction and maintenance of social status. Indeed, the eventual dependence of elites on metals as media of display and as valuable trade items was noted in both complex societies, such as that ruled by the Shang Dynasty, and in simpler societies, such as that represented by the Hopewellian Culture. However, most regions demonstrated a significant lag (often of millennia) between the initial adoption of metals and the dependence of elites upon them. Furthermore, even during periods of administrated craft specialization, many areas demonstrated elite-driven, 'industrial' production of metals concurrent with smaller, more domestic modes of production. Thus, metallurgy must be understood at multiple levels in the social spectrum and not just as part of a top-down phenomenon.

Finally, a critical part of the discussion concerned new methodological approaches used to target some of the broader themes (as mentioned above). All of the authors have been influenced by what Shimada conceptualises as a 'holistic approach,' with its emphasis on studying all aspects of the metallurgical process, including mining, fuel procurement, smelting, waste management, casting/working, use, and eventual deposition or recycling. 
For example, many papers stressed the importance of analyzing refractory ceramics such as furnaces, crucibles, and moulds, which no doubt played a critical role in the successful transfer and performance of metallurgy. Others discussed the selection and/or production of fuel sources, such as charcoal, as an important factor. Resource availability, and the effect of metallurgy upon the local environment, was also a topic of some interest, leading to suggestions of utilizing geoarchaeological and bioarchaeological methods to look for evidence of phenomena such as environmental degradation and health problems in the local communities. The importance of good, radiocarbon-dated archaeological contexts, and the use of thermoluminescence dating on metallurgical remains such as slag and furnace lining, were consistently emphasized, with many of the authors conducting their own field projects to target early metal production sites in their regions. In marked contrast to its degree of prominence in archaeometallurgy over the past two decades, none of the papers placed any significant emphasis on ethnographic analogy in making inferences about ancient metallurgical practice. This is a welcome development, demonstrating as it does the efficacy of laboratory analyses and modern excavation methods in providing answers empirically that ethnography had previously only been able to suggest by proxy.

A recurrent theme in many of these papers and during the discussion was that early metallurgy was not the premier technology in most of the ancient societies studied. In fact, metallurgical production and metal use in the initial periods of adoption and acceptance were often of minor importance relative to other crafts and materials, doing little to upstage human experiences with stones, lithics, ceramics, and bone until much later periods. What is significant about ancient metal artifacts and metallurgical production is their importance to scholars of ancient technology seeking pathways to ancient cognition and behavioral practices (à la Lechtman 1977) and to prehistorians seeking connections between distinct cultural regions. Through directed archaeological exploration in combination with rigorous laboratory analyses and nuanced anthropological understanding, ancient metallurgy provides one of the best means of exploring larger issues in the social sciences. Such issues include the interaction between changing technologies and changing societies, and the human engagement with the material worlds that they themselves construct. We hope that these papers serve as an important step in this direction, and perhaps may indicate, at least in outline form, a paradigmatic shift in archaeometallurgical research (cf. Thornton 2009).

\section{References}

Barnard, N. (1961). Bronze casting and bronze alloys in ancient China. Canberra: Australia \& Lagya.

Barnard, N. (1993). Thoughts on the emergence of metallurgy in pre-Shang and Early Shang China, and a technical appraisal of relevant bronze artifacts of the time. Bulletin of the Metals Museum, 19, 3-48.

Chernykh, E. N. (1992). Ancient metallurgy in the USSR: The early metal age. Cambridge: Cambridge University Press.

Childe, V. G. (1930). The Bronze Age. New York: Biblio and Tannen.

Childe, V. G. (1939). The Orient and Europe. American Journal of Archaeology, 43(1), 10-26.

Childe, V. G. (1944). Archaeological ages as technological stages. Journal of the Royal Anthropological Institute of Great Britain and Ireland, 74, 7-24.

Hauptmann, A., Pernicka, E., Rehren, Th., \& Yalçin, Ü. (Eds.). (1999). The beginnings of metallurgy. Der Anschnitt, b. 9. Bochum: Deutsches Bergbau-Museum.

Lechtman, H. (1977). Style in technology: Some early thoughts. In H. Lechtman \& R. S. Merrill (Eds.), Material culture: Styles, organization, and dynamics of technology (pp. 3-20). St. Paul: West Publishing.

Lechtman, H. (1979). Issues in Andean metallurgy. In E. P. Benson (Ed.), Pre-Columbian metallurgy of South America (pp. 1-40). Washington D.C.: Dumbarton Oaks. 
Lechtman, H. (1980). The Central Andes: Metallurgy without iron. In T. A. Wertime \& J. D. Muhly (Eds.), The coming of the age of iron (pp. 267-334). New Haven, CT: Yale University Press.

Maddin, R. (Ed.). (1988). The beginning of the use of metals and alloys. Cambridge, MA: MIT Press.

Muhly, J. D. (1988). The beginnings of metallurgy in the Old World. In R. Maddin (Ed.), The beginning of the use of metals and alloys (pp. 2-20). Cambridge, MA: MIT Press.

Renfrew, C. (1969). The autonomy of the south-east European Copper Age. Proceedings of the Prehistoric Society, 35, 12-47.

Renfrew, C. (1973). Before civilization. London: Penguin Books.

Renfrew, C. (1986). Varna and the emergence of wealth in prehistoric Europe. In A. Appadurai (Ed.), The social life of things (pp. 141-168). Cambridge: Cambridge University Press.

Roberts, B. W., Thornton, C. P., \& Pigott, V. C. (2009). Development of metallurgy in Eurasia. Antiquity, 83.

Smith, C. S. (1977). Metallurgy as a human experience: An essay on man's relationship to his materials in science and practice throughout history. Metals Park, OH: American Society for Metals.

Thornton, C. P. (2009). Archaeometallurgy: Evidence of a paradigm shift? In T. L. Kienlin \& B. W. Roberts (Eds.), Metals and societies: Papers in honour of Barbara Ottaway (pp. 25-33). Bonn: Habelt.

Trigger, B. G. (1969). The myth of Meroe and the African Iron Age. African Historical Studies, 2(1), $23-50$.

Wailes, B. (Ed.). (1996). Craft specialization and social evolution: In memory of V. Gordon Childe. Philadelphia: University Museum Monograph 93, University Museum of Archaeology and Anthropology, University of Pennsylvania.

Wertime, T. A. (1964). Man's first encounters with metallurgy. Science, 146(3649), 1257-1267.

Wertime, T. A. (1973a). How metallurgy began: A study in diffusion and multiple innovation. In Actes du VIIIe Congrès International des Sciences Préhistoriques et Protohistoriques (pp. 481-492). Beograd.

Wertime, T. A. (1973b). The beginnings of metallurgy: A new look. Science, 182(4115), 875-887.

Wertime, T. A., \& Muhly, J. D. (Eds.). (1980). The coming of the age of iron. New Haven: Yale University Press. 